\title{
ATRACO A LAS TRES (1962): ACTUALIZACIÓN CINEMATOGRÁFICA Y VERSIÓN TEATRAL
}

\author{
Juan A. Ríos Carratalá \\ Catedrático. Universidad de Alicante. España
}

\begin{abstract}
Resumen
El éxito popular y de crítica obtenido por Atraco a las tres (1962) ha propiciado su consideración como un clásico de la comedia cinematográfica española. En un marco de frecuentes adaptaciones al teatro de películas que han gozado de una buena respuesta del público, la comedia dirigida por José Ma Forqué fue llevada a los escenarios durante la temporada 2001-2002 y, casi simultáneamente, su guionista y productor, Pedro Masó, fue el artífice de un remake: Atraco a las tres... y media (2003). El artículo analiza los procesos de adaptación seguidos en ambos casos y las dificultades para mantener los rasgos que singularizan la popular comedia de los años sesenta.
\end{abstract}

\section{Palabras clave}

Atraco a las tres. Pedro Masó. Comedia cinematográfica. Versiones teatrales y remakes.

\begin{abstract}
The film Atraco a las tres (José Ma Forqué, 1962) is considered a classic within the genre of Spanish comedy films due to its popularity with the public and the overwhelming positive critiques. This film was readapted for the stage in the theatre season 2001-2002, while simultaneously, Pedro Masó (scriptwriter and director) readapted the classic in 2003 and called the film Atraco a las tres...y
\end{abstract}


media. This article analyses the process of adaptation for the stage and for the screen and looks at the difficulties in maintaining the unique features of this classic comedy.

\section{Key words}

Atraco a las tres - Pedro Masó - Comedy - Film remake - theatre version

\section{Introducción}

La cartelera teatral está necesitada de éxitos populares y, desde hace varias temporadas, los busca con cierta frecuencia en películas españolas y norteamericanas conocidas por el público. Su adaptación presupone una relativa garantía de cara a la taquilla. Este proceso ha conseguido resultados desiguales y ha seguido caminos que van desde la traducción al lenguaje teatral hasta la creación de nuevas y originales obras de teatro a partir de los referentes cinematográficos. No cabe, pues, una valoración global de una de las características de la cartelera contemporánea, tan necesitada de inspiración en fuentes ajenas para buscar los cauces del éxito popular.

\section{Objetivos}

El objetivo básico será el análisis de la comedia cinematográfica dirigida en 1962 por José $\mathrm{M}^{\mathrm{a}}$ Forqué en relación con su adaptación teatral y su remake impulsado por Pedro Masó, el guionista y productor de la primera. Asimismo, se establecerán los criterios seguidos en los respectivos procesos de adaptación al teatro y actualización de la comedia cinematográfica original, así como las variaciones en la clasificación genérica derivadas de dichos procesos. Finalmente, se valorará la conveniencia y oportunidad de una tarea cuyos resultados en pocas ocasiones están a la altura de las películas que se intentan recuperar para la escena o la pantalla. 


\section{Metodología}

Análisis comparativo de los elementos fundamentales de las tres obras citadas, así como de las circunstancias de producción y publicidad que propiciaron la adaptación teatral y la actualización cinematográfica de la comedia dirigida por José Mª Forqué.

Atraco a las tres fue uno de los escasos éxitos populares del teatro español durante la temporada 2001-2002. La productora Fila 7 confió en la dirección del joven Esteve Ferrer para sacar adelante la versión teatral, escrita por Blanca Suñén, de una comedia cinematográfica considerada como un clásico de nuestro cine desde poco después de su estreno a principios de los sesenta ${ }^{1}$. Había motivos para esperar la respuesta positiva del público. La película era de sobra conocida gracias a sus frecuentes pases por televisión y su divulgación en diferentes formatos audiovisuales. Contaba, además, con la poco habitual coincidencia del favor popular y de la crítica, que desde su estreno ha elogiado el trabajo de quienes intervinieron en una comedia realizada en estado de gracia por parte del guionista (Pedro Masó), el director (José $\mathrm{M}^{\mathrm{a}}$ Forqué) y, sobre todo, el extenso reparto de intérpretes con brillantes trayectorias cinematográficas: José Luis López Vázquez, Manuel Alexandre, Alfredo Landa, Agustín González, Gracita Morales, José Orjas, Rafaela Aparicio, Cassen... Los responsables del proyecto teatral imaginaban, con fundamento, que el recuerdo de este reparto permitiría esbozar una sonrisa a buena parte del hipotético público, tanto el adulto que conoció los momentos estelares de estos actores como el más joven que los ha seguido a través de la

\footnotetext{
${ }^{1}$ La película fue estrenada en Madrid el 10 de diciembre de 1962. Con un presupuesto de 4.960.000 pts, había sido clasificada como de $1^{\circ} \mathrm{B}$ con la correspondiente subvención de 1.736 .000 pts. Estos datos auguraban una discreta acogida que se vio confirmada en las primeras semanas, pero pronto aumentó su prestigio y popularidad hasta el punto de que se repuso con frecuencia durante los años sesenta, fue distribuida por numerosos países y se ha convertido en un clásico de la programación televisiva y una comedia estudiada como modelo de cine popular.
} 
televisión, donde la reposición de sus películas es una constante con buenos resultados de audiencia. El desafío consistía en que ese recuerdo, convenientemente actualizado, sirviera como acicate para acercarse a unos teatros donde otros actores, también populares, intentaban cometer un nuevo atraco a las tres en el Banco de los Previsores del Mañana.

Los responsables de Fila 7 centraron sus esfuerzos en la búsqueda de un reparto concebido para satisfacer las expectativas de un público mayoritario que se decanta por el género cómico. A pesar de contar con un buen respaldo presupuestario, esta tarea suele resultar compleja en la actualidad por la competencia que representa el cine y, sobre todo, las series televisivas que, desde hace varias temporadas, se han convertido en la fuente fundamental de la popularidad y los ingresos económicos para los actores. De hecho, el reparto sufrió frecuentes cambios a lo largo de los meses que la adaptación estuvo en cartel y sólo cuando fue estrenada en el Centro Cultural de la Villa de Madrid, enero de 2002, contó con todas las estrellas capaces de garantizar el «gancho popular»: Carmen Machín, Iñaki Miramón, Javivi y Manuel Alexandre.

La presencia de este veterano actor era fundamental de cara al supuesto homenaje a la película de José $\mathrm{M}^{\mathrm{a}}$ Forqué y, sobre todo, para la promoción en prensa de su adaptación teatral. El dossier de la productora y las entrevistas concedidas así lo prueban. Las críticas periodísticas subrayan unánimemente la emoción del actor y el público gracias a una presencia más simbólica que necesaria desde un punto de vista teatral. En la película Manuel Alexandre era el picarón Benítez que galanteaba a Gracita Morales y pedía anticipos a cuenta del atraco. Cuarenta años después, encarnaba al entrañable Don Felipe que en la comedia original había protagonizado José Orjas con su habitual acierto. El papel del veterano cómico en la versión dirigida por Esteve Ferrer tenía un carácter menor y las limitaciones de la edad lo redujeron más. No obstante, lo importante en el escenario era su mera presencia. Manuel Alexandre subrayaba la pretendida continuidad entre la película y una adaptación que buscaba la fibra sensible y nostálgica del público. 
El resto del reparto se seleccionó con la garantía del protagonismo de un Iñaki Miramón que había obtenido importantes éxitos en los escenarios con diversas comedias y la colaboración de actores populares gracias a sus apariciones televisivas. Mientras Manuel Alexandre era entrevistado para promocionar el estreno, los carteles también subrayaban la presencia en los escenarios de unos intérpretes queridos por el público de las series. Se combinaba así dos circunstancias capaces de propiciar el éxito en taquilla, aun a riesgo de no poder ensayar todos los días necesarios, admitir el lucimiento individual de algunos intérpretes y alterar el reparto con sustituciones por causa de los compromisos profesionales de quienes viven, fundamentalmente, de la televisión. El riesgo se asumía porque lo importante era crear una expectativa con las representaciones en Madrid. Después, la publicidad obtenida amortiguaría los cambios en las dadas en provincias y las reposiciones en la misma capital, que contaron con otros intérpretes seleccionados con similares criterios aunque no tuvieran tanta popularidad ${ }^{2}$. Había, por lo tanto, dos circunstancias buscadas por la productora y con gancho de cara al público: un título conocido vinculado con el humor y un reparto de los que animan la taquilla. Todo lo demás era secundario, incluso la propia adaptación y su dirección.

El éxito de la película original supone a menudo un obstáculo para su adaptación a los escenarios. Los responsables de la misma temen la posibilidad de alterar las claves de una obra conocida y exitosa. Sus esfuerzos se centran en la búsqueda de un correlato teatral para lo que ha funcionado en las pantallas. El resultado suele ser una especie de traducción, cuyo problemático encaje en el lenguaje escénico revela a menudo su origen cinematográfico. Ignoro los márgenes de actuación de Blanca Suñén a la hora de llevar a cabo la adaptación de Atraco a las tres, pero es evidente su rechazo, voluntario o no, de la posibilidad de crear una nueva obra teatral a partir del

\footnotetext{
${ }^{2}$ De acuerdo con una práctica habitual, la obra fue rodada durante el otoño de 2001 en una gira por provincias, después estrenada en Madrid con el reparto estelar y, posteriormente, inició la segunda fase de la gira que dio paso, en el otoño de 2002, a nuevas representaciones con un reparto distinto en el madrileño teatro Apolo.
} 
material aportado por la película. Su opción resulta demasiado respetuosa con la misma, incluso hasta una literalidad en la estructura y los diálogos que, paradójicamente, provoca en el escenario unos resultados distintos a los obtenidos en las pantallas. Cualquier adaptador debía ser consciente de la brillantez del guionista a la hora de crear situaciones divertidas y escribir unos diálogos con réplicas difíciles de mejorar. Pedro Masó, con la colaboración de Vicente Coello y Rafael J. Salvia, tuvo uno de sus momentos felices durante las nueve noches en las que, según sus palabras, redactó el texto que luego sería supervisado por los citados guionistas. Nada sobra ni nada falta en el guión definitivo, pero está concebido para un lenguaje cinematográfico y su traslación casi literal a los escenarios chirría con cierta frecuencia.

Bernardo Sánchez siguió una línea más independiente del texto original en su adaptación de El verdugo (1963), de Luis G. Berlanga, estrenada con gran éxito en la temporada 2000-2001 bajo la dirección de Luis Olmos. La espectacular acogida obtenida por la obra tal vez supuso un acicate para realizar, poco después, una tarea similar con la comedia de José $\mathbf{M}^{\mathrm{a}}$ Forqué. Sin embargo, los criterios seguidos en las respectivas adaptaciones fueron divergentes. Mientras Bernardo Sánchez buscó lo teatral en la película para fundamentar una obra cuya independencia resulta coherente con el respeto al original, Blanca Suñén optó por una traducción. Su literalidad origina un híbrido de dudosa correspondencia con la comedia cinematográfica. La orientación costumbrista y hasta sainetesca de la misma se transformó en una farsa cómica por el trabajo de los intérpretes y el director, pero también contribuyó una adaptación incapaz de potenciar lo teatral del guión para trasladarlo a un lenguaje distinto y, sobre todo, adecuar los contenidos a unas circunstancias alejadas de la España de los años sesenta. La preocupación por incluir todas las réplicas brillantes del original apenas permitió actualizar el planteamiento que hace de la ilusión, del sueño de superación de uno mismo, una constante capaz de superar el paso del tiempo. Este objetivo habría requerido una 
reflexión creativa más independiente del guión que, en la versión de Blanca Suñén, sólo queda podado y ordenado para hacerlo viable en un escenario.

La versión teatral de El verdugo subrayó lo universal de su contenido y sacrificó lo circunstancial, aunque tuviera un indudable atractivo y fuera de sobra conocido por los espectadores. No pretendió jugar con una nostalgia de escaso valor creativo, sino alumbrar una obra válida para el escenario y el espectador del año 2000. Así lo entendieron Bernardo Sánchez y los responsables de la compañía Teatro de la Danza cuando obviaron buena parte de los contenidos costumbristas o dejaron en un relativo segundo plano el tema de la pena de muerte. El escenario no podía recoger detalles de ambientación que quedaron grabados con especial fortuna en la película. La profundidad de campo es una posibilidad de la pantalla cuya adaptación al escenario resulta poco menos que imposible. Había que atender a lo esencial y recrearlo con la debida continuidad; hasta alcanzar la hondura capaz de hablarnos de un individuo atrapado por la vida, un verdugo de indudable actualidad al margen de que su profesión sea un recuerdo del más negro pasado.

Blanca Suñén, supongo que a instancias de la productora y en colaboración con el director, optó por una vía de menor riesgo. Resulta deudora en exceso del guión original y propicia los altibajos de una realización teatral que podía gustar al público mayoritario y la crítica, pero no aportaba nada nuevo a lo creado por la película. El homenaje se transforma así en una invitación a la nostalgia y, a partir de la misma, se anula cualquier posible vínculo de continuidad con nuestro presente. Sonreímos al recordar escenas, personajes y diálogos ahora vistos en un escenario, establecemos como espectadores las inevitables comparaciones con sus referentes cinematográficos, pero la obra se convierte en una ceremonia del recuerdo, bastante divertida y entrañable, más que en un motivo de interés desde el punto de vista estrictamente teatral.

La adaptación de Atraco a las tres resulta entretenida y hasta gozosa en medio de las sonrisas compartidas con el resto del público. También podemos justificarla como un digno homenaje a un 
título que forma parte de nuestros recuerdos. Marcos Ordóñez, en su comentario publicado en El País, afirma que «es una función desigual, con torpezas casi infantiles y grandes bajones de ritmo, pero hecha con tanto cariño a la comedia española clásica y a sus cómicos que acaba resultando simpática» (16-III-2002). De acuerdo, pero ese cariño no supone una actividad creadora y queda pendiente la pregunta de si la puesta en escena aporta algo al margen de la película original. Ninguno de sus responsables parece habérselo planteado como un requisito para su labor, resuelta siempre de acuerdo con los caminos más seguros de cara al éxito popular.

La versión teatral de Atraco a las tres respeta la localización de la historia en la España de principios de los sesenta, evocada mediante elementos añadidos como las referencias televisivas para reforzar el componente nostálgico y simpático. No obstante, lo que en la película era un presente mostrado de acuerdo con la tradición sainetesca, de plena vigencia por entonces en un cine español que actualizó su componente costumbrista (Ríos Carratalá, 1997), en la versión de Blanca Suñén y Esteve Ferrer se convierte en un motivo para la nostalgia resuelto en clave de farsa. Javier Villán, en su crítica publicada en El Mundo (14-I-2002), señala que «Ferrer aplica a la dirección un estimulante desparpajo que tiene bastante de farsa y un poco de sainete». Altera así el modelo original, verdaderamente complejo por sus equilibrios y requisitos interpretativos, para decantarse por un registro más cercano a su experiencia como actor procedente del mundo del clown y director especializado en musicales. El farsesco resultado se percibe en lo esquemático del desarrollo de las escenas, en la caracterización caricaturesca de unos tipos desprovistos del fondo social, laboral y familiar que los justificaba en la película ${ }^{3}$ y en la interpretación de los actores, que actúan con

\footnotetext{
${ }^{3}$ Esteve Ferrer pretende lo contrario en sus declaraciones a la revista Artez con motivo del estreno: «Quería que todos los personajes, desde el primero al último, tuvieran un punto más humano, más tridimensional que en la película. Aquí todos tienen un porqué, son complementarios» ( $\mathrm{n}^{\circ}$ 55, noviembre 2001). En la misma entrevista, el director afirma que los personajes de la película «parecen salidos de un cuento», lo cual nos hace pensar su escasa familiaridad con la tradición
} 
notable libertad por una falta de dirección o, tal vez, porque la misma les anime a sobreactuar como consecuencia de una desconfianza en los tipos originales. Aunque los responsables de la versión los mantengan porque forman parte de una estructura coral compensada gracias al acierto de Pedro Masó, su concreción en el escenario se vuelve más estridente y artificiosa. Desconocemos los problemas del pusilánime Cordero con su novia o el pandemónium que para el conserje Martínez supone su vuelta a casa tras la jornada laboral, pero reímos con el peculiar tartamudeo de un Javivi que opta por llevar la bufanda del Atlético de Madrid como guiño al espectador o la televisiva interpretación de Javier Calvo, sólo necesitada del subrayado de las risas enlatadas. Ambos trabajos funcionan si nos olvidamos de una comparación con los realizados por Agustín González y Cassen a las órdenes de José $\mathrm{M}^{\mathrm{a}}$ Forqué, pero tras las sonrisas es perceptible una falta de imaginación, de trabajo creativo, para superar los límites de lo previsible.

Algo similar sucede con la puesta en escena del director y la escenografía firmada por Carlos Montesinos. El respeto a la literalidad del guión provoca la necesidad de recurrir a frecuentes cambios de localización, resueltos con relativa pericia técnica, aunque escasos de imaginación para engarzarlos con la debida continuidad. Frente al ritmo y la fluidez de la comedia original, uno de los rasgos más alabados por la crítica, su versión teatral se resiente del exceso de interrupciones, fruto del intento de trasladar al escenario la literalidad de un guión con diferentes localizaciones. Una escena memorable de El verdugo, la búsqueda del protagonista por parte de la Guardia Civil en las cuevas del Drac, fue recreada por Bernardo Sánchez en un cine sin perder su significado, aportando algunas notas nuevas para enriquecer la ambientación y evitando un trasiego de localizaciones que, a pesar de las innovaciones tecnológicas, en el teatro resultan complejas y hasta agotadoras cuando se reiteran. Sin embargo, en la versión teatral de Atraco a las tres no se escatima ni un solo cambio de 
escenario y la tramoya hasta se convierte en protagonista en un momento determinado, como una especie de homenaje a los afanados técnicos. Se lo merecen, al igual que los responsables de una iluminación que permite otros cambios más rápidos y efectivos, pero queda la impresión de una falta de ritmo y continuidad, de una obra teatral que casi requiere la presencia de unos intermedios publicitarios para que no se perciba su yuxtapuesta estructura.

Estas relativas deficiencias son menores en comparación con la dificultad que supone contar con un reparto a la altura del que protagonizó la película. Pedro Masó siempre se ha considerado «el autor» de Atraco a las tres, hasta el punto de que en varias declaraciones públicas ha minusvalorado la aportación de sus colaboradores en el guión y ha comentado el escaso aprecio que el proyecto mereció a José $\mathrm{M}^{\mathrm{a}}$ Forqué y los distribuidores. Vanidades de productor al margen, el peso del film recae en unos intérpretes que se encuentran especialmente a gusto en sus papeles. Esta circunstancia facilitó que, a lo largo de un rodaje con un buen ambiente, los enriquecieran con numerosos matices. José Luis López Vázquez nunca nos recordó tanto a Groucho Marx como en su papel de «Fernando Galindo, un admirador, un esclavo, un siervo», que encabeza al grupo de inocentes atracadores. Manuel Alexandre borda a Benítez con su sonrisa irrepetible para sablear y pedir anticipos. Agustín González da las primeras muestras de su maestría en el arte del enfado. Ningún otro cómico se ha cabreado con el mismo acierto en nuestro cine. Alfredo Landa debuta en la pantalla, con un sueldo de 10.000 pts., para encarnar al tímido Castrillo, que supone un adelanto de los excelentes papeles que interpretará en Ninette y un señor de Murcia (1965) y La niña de luto (1964) a las órdenes de Fernando Fernán-Gómez y Manuel Summers, respectivamente. Gracita Morales todavía no se había encasillado en su tipo, repetido en tantas comedias de los años sesenta que popularizaron a una actriz convertida en su propia caricatura. En esta película mantiene el gracejo exhibido en Maribel y la extraña familia (1960), también de José Ma Forqué, y provoca nuestras sonrisas con su papel de secretaria pizpireta que gana un sobresueldo gracias al televisor puesto a disposición de los vecinos. 
José Orjas demuestra de nuevo que su mejor época fue la postrera de una larga trayectoria como actor de reparto, tarea en la que también aparece una Rafaela Aparicio siempre eficaz y entrañable. El convincente trabajo de Cassen, por último, permite suponer que su éxito en Plácido (1961), de Luis G. Berlanga, pudo ser menos fugaz de haberse sometido a la dirección de directores que controlaran sus excesos. En definitiva, juntar un reparto de estas características suponía la clave del éxito. Y también de la misma película, pues eran actores que estaban a gusto en unos tipos que conocían a la perfección y les permitían aportar los rasgos que les hicieron queridos por los espectadores. Pedro Masó debería compartir con ellos una mayor cuota de la autoría.

El trabajo del reparto que intervino en la versión teatral, al menos durante las representaciones en el Centro Cultural de la Villa de Madrid, fue digno y voluntarioso, coherente con un montaje donde había más voluntad de diversión que diversión, según Marcos Ordóñez. Los actores consiguieron, además, alentar la regocijada respuesta del público con recursos de probada eficacia ante espectadores que no necesariamente conocían la comedia original. Nada podemos objetar, salvo sus propias limitaciones y que tuvieran demasiado en cuenta lo realizado por sus homólogos en la película. Esta actitud, supongo que propiciada por un director poco sobrado de alternativas, les lleva a una competencia imposible y desecha otras posibilidades donde hubieran podido brillar con luz propia. La imitación suele ser poco creativa y, por el contrario, el trabajo de los intérpretes originales se desarrolló en unos términos que alentaron una creación genuina donde estaban verdaderamente a gusto. Tal vez porque intuían que este título les ayudaría a consolidar su popularidad y su carrera cinematográfica, mientras que el objetivo del reparto de la versión teatral estaba más diluido. Algunos incluso verían su trabajo en los escenarios como una interrupción de su presencia en las series televisivas, como una forma de comprobar en directo el alcance de su popularidad mediática. 
Pedro Masó siempre ha gozado de un buen olfato para conocer los gustos del público. Cuando triunfó en Atraco a las tres ya había colaborado en los guiones de varias comedias con el denominador común del éxito popular: Manolo, guardia urbano (1956), Los ángeles del volante (1957), Las chicas de la Cruz Roja (1958), El día de los enamorados (1959), Tres de la Cruz Roja (1961)... En 1962, coincidiendo con la película que nos ocupa, escribió el guión de La gran familia, uno de los títulos presentes en los recuerdos de varias generaciones. Esta condición de artífice de un cine popular nunca le ha abandonado. Resulta, pues, lógico que, en la estela del éxito obtenido por la versión teatral, el productor y guionista también sacara adelante un remake: Atraco a las tres...y media.

Pedro Masó contrató para su dirección al portorriqueño Raúl Merchand, desconocido en España y con un escaso bagaje de títulos. Sustituyó al director originalmente previsto, Joaquín Oristrell, que podría haberle dado un tono más personal a la realización mediante el recurso a una memoria compartida con los espectadores. La adaptación de este «remake muy libérrimo [sic]», según el productor, fue firmada por él y Joaquín Andujar. Para el reparto se volvió a contar con Iñaki Miramón y Manuel Alexandre, que repitieron sus papeles de la versión teatral, así como tres actores (Josema Yuste, Josep Julián y Cristina Sola) que por entonces estaban triunfando en las series televisivas y otros que con su colaboración contribuyeron a crear una película de rostros conocidos: Chus Lampeavre, Carlos Larrañaga, Pedro Reyes, Neus Asensi, Manolo Royo y Marta Fernández Muro. La nota erótica la puso Elsa Pataky, cuyo papel como la Katia Durand que seduce a Galindo pasa de ser una cantante de cabaret a una presentadora de televisión. Pedro Masó siempre encuentra con facilidad el correlato a la hora de concebir la actualización de su comedia, que suele pasar por una explicitud sin imaginación.

La acción se traslada a las fechas navideñas del 2001, cuando la inminente llegada del euro supone una oportunidad ideal para perpetrar el atraco. Fernando Galindo se erige de nuevo en el 
cabecilla de un grupo de trabajadores convertidos en atracadores, pero que han perdido buena parte del sabor costumbrista de la comedia original. Su remake resulta entretenido, el trabajo de los intérpretes es digno y la dirección está bien resuelta como una labor artesanal o de encargo. Nos encontramos ante una película en la que el productor se ha convertido de nuevo en el autor. Su actualización del guión se limita a evitar los anacronismos y a incluir situaciones eróticas o diálogos con tacos que no habrían pasado la barrera de la censura en 1962. Katia Loritz, por ejemplo, era el imposible objeto del deseo de Galindo en la comedia original, mientras que en su remake podemos disfrutar de las reiteradas apariciones de una Elsa Pataky que exhibe generosamente su belleza. Y se acuesta con Iñaki Miramón. No más profundos son otros cambios, aunque lo actualizado sea pertinente en gran medida. Así sucede con un atraco que ya no podía resultar tan ingenuo como el de 1962. Aquella oficina de los inicios de la etapa desarrollista se ha convertido en otra moderna con sofisticados medios de seguridad. Los improvisados atracadores emprenden una tarea más compleja cuyo desenlace, ante la previsible inverosimilitud, en el montaje final es elidido de forma sorprendente. No parece importar, pues prevalece el objetivo del entretenimiento con unos personajes que han pasado de ser los antihéroes de un discurso sainetesco -«gente sencilla, inocente y buena», según Pedro Masó- a émulos de un Dioni u otros personajillos del famoseo televisivo. La consecuencia es la aparición de unos tipos mucho más planos, apenas enriquecidos por los intérpretes, y una pérdida del referente costumbrista que les daba el carácter entrañable y creíble de la comedia original.

Un ejemplo clarificador lo encontramos en los divergentes finales de las dos versiones. En la original, los supuestos atracadores acaban evitando el verdadero atraco, cometido por una banda de extranjeros para la tranquilidad de la censura y los espectadores de la época. Los oficinistas son unos héroes circunstanciales que, en realidad, nunca abandonan su condición de antihéroes resignados, con la excepción de Galindo, a una vida mediocre y gris a las órdenes de Don Prudencio. En la 
nueva versión, no sólo consiguen el botín y burlar a las huestes bancarias del prepotente Otto Schültz, sino que les vemos disfrutar de los millones en un paraíso caribeño, rodeados de cocoteros y en compañía de bellezas que nos recuerdan la publicidad de las agencias de viajes. El sueño de los oficinistas se hace realidad $^{4} \sin$ que la censura de la etapa franquista nos recuerde que el mal nunca debe triunfar.

Esta libertad no supone necesariamente una mejora en el desenlace. Al igual que sucediera con antecedentes franceses e italianos (Rififi, 1955, de Jules Dassin y Rufufú, 1958, de Mario Moniceli), o con películas españolas que siguen la estela de los atracos imposibles: Los dinamiteros (1963), una insólita y amarga comedia de Juan G. Atienza, la frustración del final se impone con la lógica de un género donde el atraco tan sólo es un motivo para ilusionar a unos protagonistas que, por su condición social y económica, ni siquiera tienen el derecho de soñar. Convertirlos en millonarios en medio de hermosas mujeres y al son de ritmos caribeños supone una cesión al público mayoritario. Y resulta más conservadora que la realizada por la imposición de las normas de censura. El final agridulce, de obligada resignación que no deja en el olvido la necesidad de seguir soñando, es propio de la tradición sainetesca en la que se inserta la comedia original. El desenlace feliz y convencional de la nueva versión se ajusta mejor a una comedia de entretenimiento lista para ser olvidada a la espera de una nueva comedia con idéntico final. Por el camino hacia lo banal se han perdido píldoras como las dichas por Galindo cuando al odioso Don Prudencio, el nuevo director de la oficina, le toca la lotería jugando al número trece: «Y luego no quieren que haya revoluciones», o cuando el mismo personaje intenta imaginar un futuro al margen de las restricciones morales de su modesto pasar: «Cuando uno es rico todo vale». Son frases sueltas, probablemente ingenuas en su

\footnotetext{
${ }^{4}$ Pedro Manuel Villora, en su reseña de la versión teatral publicada en $A B C$, escribió que «Atraco a las tres pone en escena los sueños de la clase trabajadora» (15-I-2002). La afirmación es discutible y cuesta considerar a Pedro Masó como portavoz del imaginario colectivo de una clase social.
} 
búsqueda del sentido común, pero que apuntan un largo recorrido ausente en un remake donde todo se consume en la inmediatez del entretenimiento.

Atraco a las tres...y media pasó por las carteleras con la discreción de tantos otros títulos a la espera de unas emisiones por televisión para cuadrar el presupuesto. Cinco años después ya casi nadie recuerda esta comedia, mientras que la memoria de los espectadores que utilizamos este recurso como guía para evitar confusiones nos conduce a la versión original. Y no cabe la añoranza porque la podemos recuperar con absoluta facilidad. La pregunta es inevitable: ¿̇merece la pena, desde un punto de vista creativo, acometer una versión teatral o un remake cinematográfico?

\section{Conclusiones}

Los dos casos comentados evidencian una clara iniciativa comercial por parte de sus responsables. Fila 7 o Pedro Masó P.C. consideraron que el rescate de Atraco a las tres podía ser una buena oportunidad para obtener beneficios económicos. Al margen de supuestos homenajes, la versión teatral y el remake fueron concebidos con la intención de llegar al público mayoritario y todos los elementos puestos en juego son coherentes con esta lícita pretensión. Un título conocido y vinculado al humor, actores con gancho popular, directores dispuestos a realizar una adaptación nada conflictiva o arriesgada... son ejemplos del proceder de unas productoras convertidas en impulsoras de un proceso creativo cuya corrección profesional apenas rompe los márgenes de lo previsible. En tan estrecho marco todavía cabe una labor creativa a partir de una reflexión en torno a la obra original, pero resulta poco probable y destinada, en el mejor de los casos, a satisfacer las demandas de un público minoritario.

La sorpresa que supuso el éxito multitudinario de la adaptación teatral de El verdugo tiene otras claves. Bernardo Sánchez es un investigador familiarizado con la obra de Rafael Azcona desde 
hace bastantes años. No recibió un encargo que debía satisfacer en un plazo fijo, sino que a partir de los estudios publicados sobre su también amigo fue reflexionando acerca de la teatralidad de un guión que conocía a la perfección. De ese conocimiento, profundo y pausado, surgió una nueva obra coherente con la película. Se trata de un proceso cuya maduración lleva años y, desde luego, no actúa a instancias de un hipotético beneficio empresarial. La sorpresa, relativa, fue la masiva respuesta del público. La enseñanza, alentadora, fue que el trabajo bien hecho también puede ser recompensado con el éxito popular.

La versión teatral de Atraco a las tres y su remake están, por el contrario, en la línea de las películas que han pretendido actualizar otros títulos clásicos y populares de Fernando FernánGómez, la ya citada Ninette y un señor de Murcia, Edgar Neville, La vida en un hilo (1945) o el mismo José $\mathrm{M}^{\mathrm{a}}$ Forqué, la también citada Maribel y la extraña familia. Sus nuevas versiones cinematográficas (Ninette (2005), de José Luis Garci, Una mujer bajo la lluvia (1992), de Gerardo Vera y Cásate conmigo, Maribel (2002), de Ángel Blasco ${ }^{5}$ ) han sido acogidas con frialdad y, sobre todo, no han aportado nada a unos originales que, por el contrario, han desvirtuado en aspectos fundamentales. Los remakes se suelen escudar en pretendidos homenajes, pero probablemente el único que merece la pena emprender desde una perspectiva creativa sea el del reencuentro crítico con unas películas que sólo han envejecido a los ojos de quienes consideran que el presente comienza cada mañana. Esos mismos espectadores no sienten la necesidad de reencontrarse con su memoria y, por lo tanto, pueden prescindir de títulos vinculados de alguna manera con el pasado. Somos otros los que nos interesamos por ellos y, salvo excepciones, los podemos disfrutar a plena

\footnotetext{
${ }^{5}$ La película de Ángel Blasco es un título «maldito» que apenas fue difundido. En el otoño de 2005, se estrenó una versión musical de la misma comedia de Miguel Mihura bajo la dirección de Ángel Montesinos. A las pocas semanas desapareció de la cartelera madrileña en medio de un sonoro escándalo por las irregularidades cometidas por la productora. Era el año del homenaje a Miguel Mihura con motivo de su centenario, pero también de un manifiesto oportunismo de quienes, sin ningún respeto, se aprovechan de la fama del comediógrafo.
} 
satisfacción en su formato original. El único homenaje, pues, que concibo con un sentido crítico y creativo es la difusión y conocimiento de este legado cinematográfico, aunque tampoco conviene rechazar unos trabajos como los comentados. Su dignidad profesional sirvió para el regocijo de los espectadores y, supongo, alguno tendría la curiosidad de volver a ver o descubrir la divertida y sainetesca película dirigida por José $\mathrm{M}^{\mathrm{a}}$ Forqué. Ya es bastante.

\section{Bibliografía}

RÍOS CARRATALÁ, Juan A. (1997), Lo sainetesco en el cine español, Alicante, Universidad de Alicante.

SÁNCHEZ, Bernardo (2000), El verdugo, Alcobendas, Teatro de la Danza de Madrid. 